\title{
Mental health and well-being of police in a health pandemic: Critical issues for police leaders in a post-COVID-19 environment
}

\author{
Jacqueline M. Drew* and Sherri Martin ${ }^{\dagger}$
}

\begin{abstract}
Law enforcement is an occupational group that is more "at risk" of physical and psychological harm, as its members are called on to be first responders to critical incidents, terrorist attacks, natural disasters, and traumatic events. This paper explores how the COVID-19 pandemic has provided new and somewhat unique conditions under which police must serve their communities. The scope of involvement and implications for the physical and psychological health and safety of law enforcement officers across the world is unprecedented-impacting every frontline officer on every shift. Building on an evidence-based review of research from previous events such as the World Trade Center attacks on 9/11 and Hurricane Katrina, this paper develops key insights about the likely impact of COVID-19 on the mental health of police. A call to action for police chiefs and their leadership teams, including actionable recommendations to guide strategic and operational plans, is presented. Consideration must not only be given to the issues faced by police during the active COVID-19 period. Police chiefs and police leadership teams must plan and prepare now to meet the mental health legacy that COVID-19 will leave in its wake, months and possibly years later.
\end{abstract}

Key Words Police mental health; PTSD; pandemic; police leadership.

\section{INTRODUCTION}

On March 11, 2020, the World Health Organisation (WHO) declared the novel coronavirus (COVID-19) a global health pandemic. As it rapidly spread, world leaders sought to flatten the curve of infection, slow its progress, reduce fatalities, and protect their healthcare systems from collapsing. The first group to experience stress were intensive care physicians, doctors, and nurses. As with previous outbreaks, such as SARS and MERS, those called to respond to a public health emergency experienced heightened workload demands, increased exposure, and an elevated risk of infection. During the SARS outbreak, one in five cases globally were healthcare workers (Chan-Yeung, 2004).

It is now apparent that first responders-and more specifically police, who are the focus of this paper-are experiencing significant health-related impacts. Law enforcement is an occupational group that is more "at risk" of experiencing comparatively large numbers of critical incidents or traumatic events due to the nature of their work (Chopko, Palmieri \&
Adams, 2018). Weiss et al. (2010) and Chopko, Palmieri, and Adams (2015), respectively, found that police were exposed across their careers, on average, to 168 and 188 potentially traumatic events. However, unlike health workers who are involved in public health emergencies, critical incidents in policing typically involve situations such as being threatened with violence (often with a weapon), witnessing abuse of children, death, and dying, and using deadly force. The scope of involvement of law enforcement officers across the world and the implications for their physical health and safety from COVID-19 are unprecedented due to the scale of the virus's impact. COVID-19 must be recognized as a critical event that is likely to induce trauma responses.

\section{PURPOSE}

This paper considers the impacts of COVID-19 on the mental health of law enforcement personnel. The paper presents an evidence-based review that lays the foundation on which to draw key insights about the likely impact of COVID-19 on

Correspondence to: Dr. Jacqueline M. Drew, Griffith Criminology Institute, Mt Gravatt Campus, Griffith University, Queensland 4122, Australia. E-mail: i.drew@griffith.edu.au To cite: Drew, J.M., \& Martin, S. (2020). Mental health and well-being of police in a health pandemic: Critical issues for police leaders in a post-COVID-19 environment. Journal of Community Safety and Well-Being, 5(2), 31-36. https://doi.org/10.35502/jcswb.133

@) Author(s) 2020. Open Access. This work is distributed under the Creative Commons BY-NC-ND license. For commercial re-use, please contact sales@sgpublishing.ca. SgPUBLISHING Published by SG Publishing Inc. CSKA Official publication of the Community Safety Knowledge Alliance. 
police psychological well-being. It provides critical recommendations for police chiefs and their leadership teams to guide support and recovery following the current health pandemic. The mental health of police during the pandemic and, importantly, in its aftermath is discussed in the context of the literature on previous critical incidents and trauma events. For example, the World Trade Center terrorist attacks that occurred in New York on 9/11 and natural disasters, such as Hurricane Katrina, can provide relevant guidance to prepare for the likely longer-term consequences that may be experienced by police and which must be addressed by police agencies. Police chiefs and police leadership teams must plan and prepare now to meet the mental health legacy that COVID-19 will leave in its wake.

\section{CONCEPTUAL REVIEW}

\section{Defining a Critical Incident-Does COVID-19 Fit?}

A critical incident is a stressful event (trauma) that can interfere with the ability of an individual to manage everyday stress (Malcolm, Seaton, Perera, Sheehan, \& Van Hasselt, 2005). Trauma exposure includes situations where the individual experiences a threat to self and a situation where they witness a threat or harm to others (Carlier, Lamberts, \& Gersons, 1997; McCaslin et al., 2006; Stein et al. \& Strong Star Consortium, 2012). Research by Stein et al. (2012) of activeduty military found the strongest adverse posttraumatic reactions in those who had experienced situations in which there was a threat to self.

Following events such as 9/11 and Hurricane Katarina, mental health providers were encouraged to recognize two unique sub-groups: 1) first responders at higher-than-normal risk due to terrorist events; 2 ) first responders who are simultaneously rescuer-victim, including experiencing personal and family impacts of the crisis (Castellano \& Plionis, 2006). It seems that COVID-19 has added a third category, one that is potentially even more harmful due to is additive effects. First responders in the COVID-19 environment are likely to experience 1) higher-than-normal risk due to the ongoing and sustained physical threats posed by COVID-19; 2) being a rescuer-victim, specifically those who have contracted the virus as part of their duties; and 3) higher-than-normal stress due to the elevated physical danger that the job of policing poses for themselves and their families.

\section{The Intersection Between Physical and Mental Health in Policing}

COVID-19 presents critical challenges for police leadership in supporting personnel in an environment that has both physical and mental health impacts. In the COVID-19 environment it appears some lessons have been learnt from previous experiences, with much more rapid action to support law enforcement who fall ill, most notably with physical outcomes.

In the wake of the terrorist attacks of $9 / 11$, scores of first responders suffered both psychological and physical effects from their response to the disaster. Years after the attacks, some first responders developed cancers and other physical illnesses deemed to have stemmed from work performed at attack sites. However, provision of benefits and official recognition of deaths from these illnesses as "line of duty" were delayed, causing added distress for the responders and their families (see United States Department of Justice, 2018, for discussion of September 11th Victim Compensation Fund). In 2019, it was reported that 241 NYPD members died of 9/11related illnesses, compared with 23 killed in the attack10 times the deaths at the time (Katersky \& Parekh, 2019).

In the case of COVID-19, on April 9, 2020, the Bureau of Justice Assistance (BJA) (the component of the U.S. Department of Justice that administers the Public Safety Officers Benefits [PSOB] program), announced details of death benefit claims for a COVID-19-related death. It has been determined that "in the absence of evidence showing a different cause of death, BJA generally will find that the evidence shows a public safety officer who died while suffering from COVID-19 died as the direct and proximate result of COVID-19" (BJA, 2020). The U.S. Department of Labor has made changes to the procedures in the Office of Workers' Compensation Programs (OWCP) and will accept that the exposure to COVID-19 was proximately caused by the nature of the employment if the employee is a law enforcement officer or deemed to be in "high risk employment" (United States Department of Labor, n.d.). Additionally, the Fraternal Order of Police (FOP), the largest representative organization of law enforcement officers in the United States, with over 350,000 members, is actively engaged in lobbying for the passage of the "Safeguarding America's First Responders Act" (S.3607). The Act would establish a presumption that a law enforcement or other public safety officer who dies from COVID-19 or complications related to COVID-19 did so because they sustained a personal injury in the line of duty (Ripon Advance News Service, 2020).

\section{Understanding the Relationship Between Experience of and Exposure to COVID-19 and Police Mental Health Outcomes}

Evidence-based guidance for police chiefs and their leadership teams involves the critical issue of understanding the level of exposure of law enforcement to COVID-19 as an experienced trauma and, in turn, the likelihood that mental health issues will result. It is argued that COVID-19 embodies many of the elements of traumatic events that are already recognized in the law enforcement community.

\section{Personal Threat to Safety}

COVID-19 presents a real and serious risk of harm to self for police. When considering the impact of police work on the health of officers there are a number of data points. These include the number of officers who have been shot and/or killed in the line of duty and, from a mental health perspective, the number of police suicide deaths. Data released by the FOP in early May 2020 indicated that, up to that time, 93 officers had died in the line of duty due to COVID-19. Looking specifically at the New York Police Department (NYPD), with its more than 38,000 members, a city that has been an epicentre in the United States for infections, NYPD reported on 6 May 2020 that 4,652 of its members had returned to work, 452 uniformed members were out sick, and 41 members had died from COVID-19. Approximately 13\% of its entire workforce has been medically impacted. To provide a comparative view, in early May 2020, the FOP reported that 93 officers nationwide had died due to COVID-19, 91 officers had been 
shot, and 17 officers had been killed in the line of duty. From a mental health perspective, according to Blue H.E.L.P., 60 officers had died by suicide.

Key insight: The levels of sickness and death being experienced by police in the COVID-19 environment are at least comparable and are likely to exceed yearly trauma statistics.

The risks to physical health of an officer from COVID-19 are clear as they continue to work within communities which themselves are in government-mandated lockdowns due the danger of infection. In April 2020 it was reported that half of the world's population, 3.9 billion people, across 90 countries had been asked or ordered to stay at home (Sandford, 2020). In addition, there have been reports in the news media across many countries of the weaponization of COVID-19 (Chung, 2020; Griffith, 2020). This involves members of the community, often in the context of arrest, spitting on officers and claiming to be infected with the virus. In the United Kingdom, it has been reported that at least 30 officers a day are being spat on (Hayes \& Hymas, 2020).

Key insight: COVID-19 poses a significant risk of harm to self, which represents one of the most significant factors linked to poor mental health outcomes following critical incidents, traumas, and disasters.

The distribution of officers who are experiencing risk to self from COVID-19 is more widespread than in other critical incidents more commonly seen in policing. Every single officer throughout the United States involved in operational duties, and this is also true in other countries, is working in a context that presents a risk of harm-every day, on every shift. Further, COVID-19 presents a situation that is sustained and protracted and not confined to specific community cohorts or geographic areas. Reports indicate that officers who are now returning to work following COVID-19-related sick leave are fearful that they will be re-infected, given immunity to the virus remains unknown (Dazio, Sisak, \& Bleiberg, 2020).

Whilst police who responded to the World Trade Center attacks and to natural disasters such as Hurricane Katrina were required to work over a period of time under traumainducing conditions, we need to be prepared that police may work in an active COVID-19 era much longer. This pandemic also necessitates the return of officers to the exact situation, if not a riskier policing environment, that previously impacted on their physical health.

Key insight: The geographic distribution of COVID-19 and its potential impact on all police officers is unprecedented and includes new challenges not previously experienced.

\section{Impact on Families}

Whilst the sustained and protracted nature of the stress experienced by officers themselves may be harmful, the pandemic, like other traumas, also has significant implications for police families. It is argued that the likelihood that negative spill-over will occur is exacerbated by the circumstances and nature of COVID-19. In the aftermath of Hurricane Katrina, many police had to cope with the impact of the hurricane on themselves and their families: many had lost homes, were without power and water, and did not return home for extended periods. It was reported that almost $80 \%$ of officers had their homes destroyed (Sims, 2007). In their review of policing disasters, Faust and Vander Ven (2014) described Hurricane Katrina as a worst-case scenario, as police were both victims and responders. Of relevance to this discussion, research undertaken by West et al. (2008) found that having a family member injured during the crisis was predictive of PTSD and depression, and having one's house rendered uninhabitable was predictive of depression.

Key insight: Critical incidents, trauma, and disasters that directly spill over and impact on personal and family life, which are clearly present in a COVID-19 context, are associated with greater likelihood of poor mental health outcomes for police.

Further, in the circumstances of COVID-19, which are different to those we have seen in other events, officers are fearful of bringing home the virus to their families. In turn, it is likely that family members simultaneously worry about their police officer family member and the risk that the job of policing is now directly imposing on them. In the case of COVID-19, the job of a police officer is directly impacting the health and safety of family members to an extent that is atypical. Given these relatively unique circumstances of $\mathrm{CO}-$ VID-19, research as to the resultant prevalence rates of stress and subsequent mental health problems for police families is unknown. It is likely that usual levels of stress caused by the "routine" danger of police work will be significantly increased in the COVID-19 context.

Key insight: The COVID-19 environment is likely to exacerbate stress that is being experienced by both officers and their families.

\section{Rates of PTSD and Other Mental Health Problems}

The prevalence of PTSD in police and first responders is associated with critical incidents and disasters, and it is interesting to examine rates of prevalence following different types of events. Overall prevalence of PTSD within police populations has been estimated to be between $7 \%$ and $19 \%$ (Faust \& Vander Ven, 2014). Carlier et al. (1997) reported that the prevalence of PTSD amongst police officers involved in a single traumatizing event is around $7 \%$. Based on a metaanalytic review of the literature, first responders in the first four years following 9/11 had a probable PTSD prevalence rate of between $8 \%$ and $12 \%$ (Lowell et al., 2018). It was reported that, shortly after Hurricane Katrina, 19\% of officers reported PTSD symptoms and 26\% reported symptoms of Major Depressive Disorder (West et al., 2008). Unsurprisingly, it is likely that different types of traumatic experiences will produce different prevalence rates in the short term.

We know that police need support during crises. However, longer-term impacts have also been documented. Symptoms often decrease post-disaster. For example, Brauchle (2006; cited in Bowler et al., 2012) reported that for rescue workers (including police) attending a natural disaster in Austria, PTSD symptoms fell from $25.7 \%$ after six weeks to $6.3 \%$ at six months post-incident. However, research studies 
on rates of probable PTSD of police involved in 9/11 found that rates increased over time (Bowler et al., 2012). PTSD and comorbid depression and anxiety can develop after a delay of up to six years following such life-threatening events (Pole et al., 2001).

Key insight: Identification of the prevalence rates of PTSD and other mental health concerns during, immediately following, and in the years after COVID-19 is needed.

Drawing from research on $9 / 11$, the three strongest predictors of probable PTSD over time were injury, losing someone to the event, and witnessing horror (Liu, Tarigan, Bromet, \& Kim, 2014). If we consider the circumstances of COVID-19, it may be particularly important for police agencies to focus on and track the longer term psychological outcomes for officers who themselves were infected by the virus and/ or who lost someone, whether that be a fellow officer or a member of their own family.

Key insight: Identification of groups that may be at greater risk of PTSD and other mental health concerns based on their personal experiences of COVID-19 is warranted.

It may be that the trajectory of mental health conditions is influenced by the type of critical incident or natural disaster being experienced. Given the somewhat unique nature of COVID-19 compared with other types of traumas experienced by police, police leaders must invest in monitoring programs. Through monitoring programs established after 9/11 we have been able to understand the trajectory of PTSD and associated psychological outcomes many years after the attacks.

Key insight: Tracking the specific trajectory of COVID-19, a potentially new type of critical incident/trauma event, is needed.

It must also be recognized that the impact of COVID-19 is unlikely to be confined to PTSD. Many officers may experience symptoms that do not meet the full PTSD diagnostic criteria and/or are suffering from other mental health concerns, such as depression and anxiety. Police responders to 9/11 reported subsyndromal PTSD at a rate of $15.4 \%$, significantly higher than the $5.4 \%$ of police who met the criteria for PTSD (Pietrzak et al., 2012). Subsyndromal PTSD "was associated with substantially elevated rates of comorbid psychiatric disorders, functional difficulties, somatic symptoms, and perceived needs for mental health care" (Pietrzak et al., 2012, p. 840).

Key insight: Recognition and awareness of the full range of psychological outcomes resulting from COVID-19 is critical and should not be confined only to PTSD diagnoses.

\section{Mental Health Responses to Critical Incidents and Disasters}

Police leaders must consider what programs and initiatives are needed to support the psychological outcomes of COVID-19. While it is beyond the scope of this paper to fully review mental health approaches, a number of relevant themes are highlighted.

Among the most recognized interventions in policing and elsewhere is Critical Incident Stress Management (CISM). CISM is characterized by crisis intervention designed to be used as "emotional first aid" to stabilize and restore pre-crisis functioning (Mitchell \& Everly, 1996). For many years, Critical Incident Stress Debriefing (CISD) or psychological debriefing was used, until it was established that evidence to support its use was lacking (Bastos, Furuta, Small, McKenzie-McHarg, \& Bick, 2015; Roberts, Kitchiner, Kenardy, Lewis, \& Bisson, 2019; Rose, Bisson, Churchill, \& Wessely, 2002). Other approaches included Mental Health First Aid (MHFA) training (Intveld, 2016) and psychological first aid programs, such as Recognize, Evaluate, Advocate, Coordinate, and Track (REACT) (Marks et al., 2017).

Castellano and Plionis (2006) compared three models of intervention: psychological first aid, CISM, and the FEMA/ SAMSHA Crisis Counseling Program (CCP). The three approaches use similar frameworks, and all include a peer support component. Based on the lack of consistent outcomes of the interventions, Castellano and Plionis (2006) concluded that fluidity in intervention technique is needed, with customized and effective treatment dictated by the individual needs of the client in each unique and specific environment.

More rigorous program evaluations are needed to make stronger conclusions about the effectiveness of interventions (Bledsoe, 2003; Roberts et al., 2019). For example, despite several evaluation studies of CISM, one of the most commonly used crisis intervention approaches, its effectiveness continues to be debated (Bledsoe, 2003). Some studies have indicated that specific elements of the intervention may in fact exacerbate symptoms and be harmful (Bledsoe, 2003). Further, as demonstrated by Castellano and Plionis (2006), the interrelationship between client and environment may result in different outcomes.

The environment, circumstances, and impacts of the pandemic as experienced by police are somewhat unique. Even commonly used interventions may not be applicable, as evidence supporting even the more established methods is inconclusive, and customised versions of interventions may need to be developed. Typical responses to mental health effects of exposure currently involve interventions that focus on acute trauma. Determining how effective they will be with respect to COVID-19, a crisis that has the potential to last much longer, is difficult to judge.

Key insight: Given that evidence regarding the most effective mental health programs and initiatives in a post COVID-19 context is not definitive, it is likely that a suite of programs should be provided in both the short and longer term.

\section{KEY RECOMMENDATIONS FOR POLICE CHIEFS AND LEADERSHIP TEAMS}

Based on the findings of this paper and the key insights drawn, a call to action is urgently needed to support police personnel as they continue to experience the stresses of an active COVID-19 environment. Of equal importance is the need to strategically plan for post-pandemic. 
Recent efforts to support law enforcement responses during the COVID-19 pandemic must be acknowledged. For example, both the International Association of Chiefs of Police (IACP) and the FOP have developed dedicated webpages specifically focused on dissemination of pertinent pandemic-relevant information, including physical health and safety recommendations (IACP, 2020; FOP, n.d.). Similarly, the Collaborative Reform Initiative Technical Assistance Center (CRI-TAC), consisting of the COPS office and nine other leading law enforcement agencies, has dedicated a portion of its efforts to providing resources to law enforcement for keeping themselves healthy during the pandemic (United States Department of Justice, n.d.).

Information is being provided in some forums on accessing mental health and wellness services, but there are few recommendations for coping in the longer term. There does not appear to be any advice to officers about the notion that, while they may not experience immediate distress, delayed psychological effects can be expected and they should monitor their psychological health over time and seek support even following the pandemic.

The specific recommendations below are made to assist police chiefs and their leadership teams in meeting the challenges they will likely face in a post-COVID-19 policing environment.

\section{Support}

Recommendation: Adequate support services should be available to assist officers in managing their mental health during the active COVID-19 period and provide continued access to support in the longer term.

Recommendation: Support programs should be numerous and multi-faceted as evidence demonstrating the effectiveness of current crisis intervention programs in the unique circumstances of COVID-19 is unclear.

Recommendation: Police agencies need to develop a methodology for identifying specific cohorts of police that may require additional support-those that are at higher risk due to greater trauma exposure.

Recommendation: Police agencies need to educate their police personnel on the delayed impact of COVID-19 for themselves and their families, ensuring understanding that mental health concerns are not necessarily immediate and that support is appropriate and available in the longer term.

\section{Monitoring}

Recommendation: Monitoring should go beyond PTSD and recognize psychological issues, such as depression and anxiety.

Recommendation: Police agencies need to be agile and able to identify officers that may not have reported symptoms during the COVID-19 active period but have delayed symptomology.

Recommendation: Monitoring should include police families, considering both the impact on the relationships of officers in the context of their family unit and the stress and mental health outcomes for families.

\section{Evaluation}

Recommendation: Police agencies need to monitor the use of support services in line with the numbers of officers in their agencies that report mental health problems.

Recommendation: Police agencies need to conduct ongoing evaluations of support services, ensuring that programs and initiatives are evidence-based and serve to maximally impact on improving police mental health.

CONFLICT OF INTEREST DISCLOSURES

The authors declare that there are no conflicts of interest.

\section{AUTHOR AFFILIATIONS}

*Griffith Criminology Institute, Griffith University, Brisbane, Queensland, Australia; 'Fraternal Order of Police, Nashville, TN, USA.

\section{REFERENCES}

Bastos, M. H., Furuta, M., Small, R., McKenzie-McHarg, K., \& Bick, D. (2015). Debriefing interventions for the prevention of psychological trauma in women following childbirth. Cochrane Database of Systematic Reviews, 10(suppl 4), CD007194.

Bledsoe, B. E. (2003). Critical incident stress management (CISM): Benefit or risk for emergency services? Prehospital Emergency Care, 7(2), 272-279

Bowler, R. M., Harris, M., Li, J., Gocheva, V., Stellman, S. D., Wilson, K., ... Cone, J. E. (2012). Longitudinal mental health impact among police responders to the 9/11 terrorist attack. American Journal of Industrial Medicine, 55, 297-312.

Bureau of Justice Assistance. (2020). Public safety officers' benefits program - coronavirus/COVID-19 update, April 2020. Retrieved from https://bja.ojp.gov/sites/g/files/xyckuhl86/files/media/ document/psob-covid19-4-2020.pdf

Carlier, I. V., Lamberts, R. D., \& Gersons B. P. (1997). Risk factors for posttraumatic stress symptomatology in police officers: a prospective analysis. Journal of Nervous Mental Disorder, 185, 498-506.

Castellano, C., \& Plionis, E. (2006). Comparative analysis of three crisis intervention models applied to law enforcement first responders during $9 / 11$ and Hurricane Katrina. Brief Treatment and Crisis Intervention, 6(4), 326-336.

Chan-Yeung M. (2004). Severe acute respiratory syndrome (SARS) and healthcare workers. International Journal of Occupational Environmental Health, 10, 421-427.

Chopko, B. A., Palmieri, P. A., \& Adams, R. E. (2018). Relationships among traumatic experiences, PTSD, and posttraumatic growth for police officers: A path analysis. Psychological Trauma: Theory, Research, Practice and Policy, 10(2), 183-189.

Chopko, B. A., Palmieri, P. A., \& Adams, R. E. (2015). Critical incident history questionnaire replication: Frequency and severity of trauma exposure among officers from small and midsize police agencies. Journal of Traumatic Stress, 28, 157-161

Chung, F. (2020). Coronavirus Australia: "Beyond belief" police officers spat on while enforcing social distancing. News.com.au. Retrieved from https://www.news.com.au/lifestyle/health/health-problems/ coronavirus-australia-beyond-belief-police-officers-spat-on-whileenforcing-social-distancing/news-story/Od47edc232ff279e19ae0 $1865 d 7 f 2 b 2 b$

Dazio, S., Sisak, M. R., \& Bleiberg, J. (2020). After COVID-19 recovery, first responders get back to work. US News. Retrieved from https:// www.usnews.com/news/health-news/articles/2020-04-27/aftercovid-19-anxious-wary-first-responders-back-on-job 
Faust, K. L., \& Vander Ven, T. (2014). Policing disaster: An analytical review of the literature on policing, disaster, and post-traumatic stress disorder. Sociology Compass, 8(6), 614-626.

Fraternal Order of Police (FOP: n.d.). COVID-19 Information for Law Enforcement: Protecting Public Safety and Health. Retrieved from https://fopcovid19.org/

Griffith, J. (2020). Man spit on officers, claimed to have COVID-19 during domestic incident arrest, police say. NBC News. Retrieved from https://www.nbcnews.com/news/us-news/man-spit-officersclaimed-have-covid-19-during-domestic-incident-n1184356

Hayes, G., \& Hymas, C. (2020). At least 30 officers a day are being spat or coughed at, as a police leader demands jail for "weaponising" coronavirus. The Telegraph. Retrieved from https://www.telegraph. co.uk/news/2020/04/24/least-30-officers-day-spat-coughedpolice-leader-demands-jail/

International Association of Chiefs of Police (IACP). (2020, March 9). Law Enforcement Information on COVID-19. Retrieved from https://www. theiacp.org/resources/document/law-enforcement-information-oncovid-19

Intveld, R. (2016) Expanding the role of EAP through peer support. The Journal of Employee Assistance, 46(4), 20-24.

Katersky, A., \& Parekh, S. (2019). 241 NYPD officers have died from 9/11 illnesses, 10 times the number killed in World Trade Center attack. ABC News. Retrieved from https://abcnews.go.com/US/241-nypdofficers-died-91 1-illnesses-10-times/story? id =65430201

Lowell, A., Suarez-Jimenez, B., Helpman, L., Zhu, X., Durosky, A., Hilburn, D. A., ... Neria, Y. (2018). 9/11-related PTSD among highly exposed populations: A systematic review 15 years after the attack. Psychological Medicine, 48, 537-553.

Liu, B., Tarigan, L. H., Bromet, E. J., \& Kim, H. (2014). World Trade Center disaster exposure-related probable posttraumatic stress disorder among responders and civilians: A meta-analysis. PLOS One, 977), e101491. doi:10.1371/journal.pone.0101491

Malcolm, A. S., Seaton, J., Perera, A., Sheehan, D. C., \& Van Hasselt, V. B. (2005). Critical incident stress debriefing and law enforcement: An evaluative review. Brief Treatment and Crisis Intervention, 5(3), 261-278.

Marks, M., Bowers, C., DePesa, N., Trachik, B., Deavers, F., \& James, N. (2017). REACT: A paraprofessional training program for first responders-A pilot study. Bulletin of the Menninger Clinic, 81(2), $150-166$

McCaslin, S. E., Rogers, C. E., Metzler, T. J., Best, S. R., Weiss, D. S., Fagan, J. A., ... Marmar, C. R. (2006). The impact of personal threat on police officers' responses to critical incident stressors. Journal of Nervous Mental Disorder, 194, 591-597.

Mitchell, J. M., \& Everly, G. S. (1996). Critical incident stress debriefing: An operations manual for the prevention of traumatic stress among emergency services and disaster workers (2nd ed.). Elliot City, MD: Chevron Publishing Corp.
Pietrzak, R. H., Schechter, C. B., Bromet, E. J., Katz, C. L., Reissman, D. B., Ozbay, F., ...Southwick, S. M. (2012). The burden of full and subsyndromal postraumatic stress disorder among police involved in the World Trade Center rescue and recovery effort. Journal of Psychiatric Research, 46, 835-842.

Pole, N., Best, S., Weiss, D., Metzler, T., Liberman, A., Fagan, J., Marmar, C. (2001). Effects of gender and ethnicity on duty-related posttraumatic stress symptoms among urban police officers. Journal of Nervous Mental Disorder, 18917), 442-448.

Ripon Advance News Service. (2020). Tillis introduces bipartisan bill to safeguard benefits for nation's first responders. Retrieved from https://riponadvance.com/featured/tillis-introduces-bipartisan-billto-safeguard-benefits-for-nations-first-responders/

Roberts, N. P., Kitchiner, N. J., Kenardy, J., Lewis, C. E. \& Bisson, J. I. (2019). Early psychological intervention following recent trauma: A systematic review and meta-analysis. European Journal of Psychotraumatology, 10(1), doi:10.1080/20008198.2019.1695486

Rose, S. C., Bisson, J., Churchill, R., \& Wessely, S. (2002). Psychological debriefing for preventing post traumatic stress disorder (PTSD). Cochrane Database of Systematic Reviews, (2), CD000560.

Sandford, A. (2020). Coronavirus: Half of humanity now on lockdown as 90 countries call for confinement. Euro News. Retrieved from https://www.euronews.com/2020/04/02/coronavirus-in-europespain-s-death-toll-hits-10-000-after-record-950-new-deaths-in-24-hou

Sims, B. (2007). The day after the hurricane: Infrastructure, order, and the New Orleans Police Department's response to Hurricane Katrina. Social Studies of Science, 37111, 111-118.

Stein, N. R., Mills, M. A., Arditte, K., Mendoza, C., Borah, A. M., Resick, P. A., ... Strong Star Consortium. (2012). A scheme for categorizing traumatic military events. Behavior Modification, 36(6), 787-807.

United States Department of Justice. (2018, April 16). September 17th Victims Compensation Fund. Retrieved from https://www.justice. gov/civil/vcf

United States Department of Justice Community Oriented Policing Services. (n.d.). CRI-TAC: Collaborative Reform Initiative Technical Assistance Center. Retrieved from https://cops.usdoj.gov/ collaborativereform

United States Department of Labor. (n.d.). Claims under the Federal Employees' Compensation Act due to the 2019 Novel Coronavirus (COVID-19). Retrieved from https://www.dol.gov/owcp/dfec/ InfoFECACoverageCoronavirus.htm

Weiss, D. S., Brunet, A., Best, S. R., Metzler, T. J., Liberman, A., Pole, N., ... Marmar, C. R. (2010). Frequency and severity approaches to indexing exposure to trauma: The Critical Incident History Questionnaire for police officers. Journal of Traumatic Stress, 23, 734-743.

West, C., Bernard, B., Mueller, C., Kitt, M., Driscoll, R., \& Sangwoo T. (2008). Mental health outcomes in police personnel after Hurricane Katrina. Journal of Occupational and Environmental Medicine, 50(6), 689-695. 